\title{
The use of diuretics in acute heart failure: Evidence based therapy?
}

\author{
Ali Vazir ${ }^{1 *}$, Martin R. Cowie ${ }^{2}$ \\ ${ }^{1}$ Cardiology and Critical Care (HDU), Royal Brompton Hospital, National Heart and Lung Institute, Imperial College London, \\ London, UK \\ ${ }^{2}$ Cardiology, Royal Brompton Hospital, Imperial College London, London, UK \\ Email: ${ }^{\text {a.vazir@imperial.ac.uk, m.cowie@imperial.ac.uk }}$
}

Received 20 January 2013; revised 19 March 2013; accepted 21 April 2013

Copyright (C) 2013 Ali Vazir, Martin R. Cowie. This is an open access article distributed under the Creative Commons Attribution License, which permits unrestricted use, distribution, and reproduction in any medium, provided the original work is properly cited.

\begin{abstract}
The evidence base for the use of diuretics in acute heart failure is limited, with no large double-blind placebo-controlled randomized trials. However, their use as a first line treatment of acute heart failure is firmly established in clinical practice, and endorsed in clinical guidelines. Loop diuretics are typically the first line diuretic strategy for the treatment of acute heart failure. For patients with considerable fluid retention, there is some evidence that initial treatment with continuous infusion or boluses of high dose loop diuretic is superior to an initial lower dose strategy. In patients who are diuretic resistant, the addition of an oral thiazide or thiazide-like diuretic to induce sequential nephron blockade can be beneficial. Intravenous low-dose dopamine has also been used to assist diuresis and preserve renal function in such circumstances, but trials are underway to confirm the clinical value of this agent. Mechanical ultrafiltration has been used to treat patients with heart failure and fluid retention, but the evidence base is not secure, and its place in clinical practice is yet to be established.
\end{abstract}

Keywords: Acute Heart Failure; Diuretics; Diuretic Resistance; Ultrafiltration

\section{INTRODUCTION}

There is no universally agreed definition of acute heart failure, but it is generally considered to represent the relatively abrupt onset of symptoms severe enough to merit hospitalization. It can occur de novo, or in patients with chronic heart failure, in whom it is termed acute decompensated heart failure. In extreme cases, cardiogenic shock

"Corresponding author. may be present where there are symptoms of poor organ perfusion as a consequence of low cardiac output and a low blood pressure.

Fluid retention or shift is a key feature of acute heart failure, manifesting as ankle swelling, ascites, and/or pulmonary edema. Therapeutic strategies to control fluid balance, and to shift fluid out of the interstitium, lead to significant symptomatic relief and improved health-related quality of life.

Before modern diuretics were available, the treatment of fluid retention was limited to the use of such mechanical measures as rotating tourniquets to reduce preload, Southey tubes inserted through the skin to drain fluid [1] and venesection [2]. In 1785, digoxin, given in the form of foxglove, was also reported to have a diuretic effect, as observed by William Withering, and was the treatment of choice for dropsy, a condition characterized by congestion [3].

The first diuretics that were available were mercurial diuretics given via intramuscular injections [4]: their effect was discovered coincidentally when patients were treated with these drugs for syphilis. The treatment of fluid retention in heart failure was revolutionized with the development of thiazide diuretics in the 1950s [5] and loop diuretics in the 1960s [6].

The clinical evidence for the efficacy of diuretics in reducing the symptoms of heart failure is based on clinical experience and relatively small-randomized studies. Most clinical practice guidelines on the management of heart failure have given diuretic therapy a "Class I" recommendation (evidence and/or general agreement that a given treatment or procedure is beneficial, useful or effective), with a level of evidence based on expert opinion for relief of symptoms of congestion in patients presenting with fluid retention $[7,8]$.

In the most recent European guidelines on heart failure [8] diuretics are recommended for the relief of dyspnea 
and edema in patients with signs and symptoms of congestion, irrespective of left ventricular ejection fraction, with the stated aim of achieving and maintaining euvolemia with the lowest achievable dose. It is acknowledged that the dose must be adjusted, particularly after restoration of "dry body weight", to avoid the risk of intravascular volume depletion and dehydration, which can lead to hypotension, renal dysfunction and the inability to introduce disease modifying therapies such as angiotensin converting enzyme inhibitors, beta-blockers and mineralocorticoid receptor antagonists.

In this review we discuss the evidence base for the use of these modern diuretics in the management of acute heart failure.

\section{TYPES OF DIURETIC}

There are four pharmacological classes of diuretics used in $\mathrm{HF}$ :

a) Loop diuretics (furosemide, bumetanide, torasemide, ethacrynic acid);

b) Thiazide diuretics (hydrochlorothiazide, bendroflumethazide, or the "thiazide-like" metolazone);

c) Directly acting potassium-sparing diuretics (amiloride and triamterene);

d) Mineralocorticoid receptor antagonists (spironolocatone, canrenoate and eplerenone).

\subsection{Loop Diuretics}

Loop diuretics are the most commonly used diuretics for HF. They act on the ascending limb of the loop of Henle, blocking the reabsorption of up to $20 \%-30 \%$ of filtered sodium by inhibiting the sodium, potassium and chloride co-transporter. This results in an intense, and usually short-lived, diuresis. The drug must be delivered to the lumen of the nephron and is thus dependent on glomerular filtration being sufficiently preserved.

Loop diuretics have a rapid onset of action, working within minutes when given intravenously or within 30 minutes when given orally [9]. They have a short halflife, so their action is usually of short duration, and consequently they may have to be given several times in a day to maintain the diuretic effect, and to minimize rebound sodium reabsorption. They can be administered orally, or intravenously as a slow injection or an infusion.

All the loop diuretics are roughly equivalent in terms of efficacy but oral bumetanide has higher bioavailability, so may be more useful than oral furosemide in patients with marked fluid retention or gut absorption problems. Bumetanide is more potent than furosemide with a 1:40 dose equivalence. Torasemide has a longer half-life (3 4 hours), therefore can be given less frequently than furosemide or bumetanide. Bumetanide and torasemide un- dergo hepatic elimination, as opposed to furosemide which undergoes renal elimination, therefore the latter is likely to accumulate with renal impairment. Absorption of oral loop diuretics can be delayed by food. Nonsteroidal antiinflammatory drugs blunt the natriuretic response to all of the loop diuretics by preventing the prostaglandininduced rise in renal blood flow that accompanies and sustains the natriuretic response to loop diuretics. This effect is not seen with low-dose aspirin $(<1 \mathrm{mg} / \mathrm{kg} /$ day $)$ [10].

All loop diuretics, but particularly furosemide, cause changes in systemic hemodynamics that are initially unrelated to the degree and extent of natriuresis that they induce. Short-term administration of furosemide leads to a rapid increase in venous capacitance and a decline in cardiac filling pressure, coincident with a rise in plasma renin activity. This effect predominates over any rise in systemic vascular resistance in patients with pulmonary edema or decompensated acute heart failure [11]. This effect is maximized at an intravenous dose of $20 \mathrm{mg}$ [12].

All of the loop diuretics possess some ototoxicity, with ethacrynic acid the worst. Transient hearing loss may occur in patients receiving rapid intravenous bolus injection-so injection at a rate $>4 \mathrm{mg} /$ minute is not advisable. Permanent sensorineuronal hearing loss may occur at doses equivalent to furosemide $1000 \mathrm{mg}$ per day [13].

\subsection{Thiazide and Thiazide-Like Diuretics}

Thiazide diuretics act on the distal tubule, where they inhibit sodium and chloride reabsorption, and block 10\%$15 \%$ of sodium reabsorption. They cause a slower onset ( 1 - 2 hours) and more prolonged (12 - 24 hours) but milder diuretic effect compared to a loop diuretic. Rebound sodium reabsorption is unlikely to occur. Despite thiazide diuretic having a less potent diuretic effect, their long duration of action allows a similar degree of sodium excretion to occur throughout a 24-hour period as compared to a loop diuretic [14]. Thiazides are more likely to result in hypokalemia and nocturia as they have a longer duration of action. Thiazides on their own are largely ineffective if glomerular filtration rate is below $30 \mathrm{ml} /$ min, but they may be useful in combination with a loop diuretic in patients who have refractory edema.

Metolazoneacts like a thiazide, but in addition it acts on the proximal tubule where $60 \%-70 \%$ of sodium is reabsorbed. Therefore metolozone can result in a profound diuresis when combined with a loop diuretic. It appears to be effective even in moderate renal dysfunction [15]. Such combination usage is typically only required for a few days in most cases of resistant fluid retention.

\subsection{Potassium Sparing Diuretics}

Potassium sparing diuretics (such as amiloride) produce 
a mild diuretic effect by blocking the sodium/potassium exchange pump in the distal tubule. This exchanger is highly active in patients with HF who are on the combination of a loop and thiazide diuretic. As they have a weak diuretic effect, they are mainly used in combination with thiazide or loop diuretics to prevent hypokalemia $[16,17]$, as they appear to be more effective than potassium replacement [18]. There is a risk of hyperkalemia, particularly in patients with renal dysfunction [19].

Aldosterone (mineralocorticoid) receptor antagonists are mainly used at low dose as neuro-hormonal blockers, for prognostic benefit, rather than as diuretics per se. However, in patients with right sided heart failure, liver impairment and ascites, characterized by very high circulating levels of aldosterone, higher doses of spironolactone (typically, 200 - $400 \mathrm{mg} /$ day) are often used for their diuretic effect.

Common side effects of diuretics most frequently used in ADHF are summarized in Figure 1.

\section{EVIDENCE BASE FOR THE USE OF DIURETICSIN ACUTE HEART FAILURE}

The evidence based for the use of diuretics in acute heart failure is limited. Trials of diuretics in HF patients with a description fitting the contemporary definition of ADHF such as hospitalized patients with worsening symptoms, or those with NYHA II-III characterized by fluid retention are described and are summarized in Figure 2. Trials not fitting this description were not included.

\subsection{Placebo-Controlled Trials of Diuretics}

Placebo-controlled randomized trials of diuretic therapy for the treatment of heart failure are limited to studies that include small number of patients (3 - 247 patients). However, all of these studies reported that diuretics significantly improved symptoms in heart failure [20-25]. None was powered to estimate the effect on mortality,

Common side effects of diuretics used in acute decompensated heart failure

\author{
Hypokalaemia with loop and thiazides \\ Hyperkalaemia with potassium sparing diuretics \\ Hyponatreamia more frequent with thiazides than loop \\ Impaired glucose metabolism with loop and thiazides \\ Oto-toxicity with high dose loop \\ Acute Gout with loop and thiazide \\ Activation of RAAS and sympathetic nervous system leading to progression of LV dysfunction.
}

Figure 1. Common side effects of diuretics used in acute decompensated heart failure.

\begin{tabular}{|c|c|c|c|c|c|}
\hline Trials of diuretics for ADHF & Sample size & Population studied & Trial design & Diuretic drug & Outcomes \\
\hline \multicolumn{6}{|l|}{ Placebo-controlled trials } \\
\hline Kouroukli, 1976 (20) & 30 & ADHF & Cross-over & Bumetanide vs Furosemide Vs Placebo & Effective water excretion with both loop diuretics \\
\hline Haerer, $1990(21)$ & 60 & NYHA II-III & Unblinded, controlled, non-randomised & Piretanide Vs Placebo & $\begin{array}{l}\text { Improvement in all clinical and hemodynamic } \\
\text { parameters in the absence significant side effects }\end{array}$ \\
\hline Kleber, 1990 (22) & 247 & Mild CHF & multicentre, double-blind, double-dummy, randomised & Oral HCT Vs Ibopamine Vs HCT + Ibopamine Vs Placebo & Greater reduction in body weight with diuretics \\
\hline Sherman, 1986 (24) & 38 & Mild-moderate CHF & double blind, randomised, parallel & Piretanide Vs placebo & At 28 days, improved symptoms with piretanide \\
\hline \multicolumn{6}{|l|}{ Thiazide versus loop diuretic } \\
\hline Stewart, 1965 (25) & 11 & ADHF, Resistant oedema & cross-over trial & furosemide Vs bendrofluazide Vs Ethacrynic acid & $\begin{array}{l}\text { Fusrosemide at doses of } 200 \mathrm{mg} \text { leads to effective } \\
\text { diuresis, similar to ethacrynic acid, and better } \\
\text { than bendrofluazide }\end{array}$ \\
\hline Gonska, 1985 (28) & 30 & NYHA II-III & open, controlled, randomised study & Piretanide Vs Hydrochlorthiazide-triamterene & $\begin{array}{l}\text { Significant Weightloss in both groups. Piretanide } \\
\text { group were more recompensated (10 Vs } 4) \text {. }\end{array}$ \\
\hline Gabriel, 1981 (29) & 18 & Eldelrly with cardiac oedema & cross-over trial design & Bendrofluazide, frusemide and bumetanide & $\begin{array}{l}\text { Bumetanide least change in plasma potassium } \\
\text { compare to bendrofluazide }\end{array}$ \\
\hline \multicolumn{6}{|c|}{ Comparison between loop diuretics } \\
\hline Noe, 1999 (31) & 240 & NYHA II-III & prospective study, randomised & Torasemide Vs Furosemide & $\begin{array}{l}\text { At } 6 \text { months, Torasemide group were heavier but had } \\
\text { better quality of life at } 1 \text { month only. }\end{array}$ \\
\hline Stroupe, $2000(32)$ & 193 & ADHF & prospective, randomised, non-blind study & Torasemide Vs Furosemide & $\begin{array}{l}\text { At } 1 \text { year Torasemide lead to lower Readmission to } \\
\text { hopsitalisation } 18 \mathrm{Vs} 34 \% ; P=0.013 \text {. } \\
\text { Torasemide was more cost-effective. }\end{array}$ \\
\hline Murray, 2001 (33) & 234 & ADHF & open-label trial & Oral Torasemide Vs Furosemide & $\begin{array}{l}\text { less readmission with torasemide } 32 \text { Vs } 19 \% \text {; p<0.01 } \\
\text { at } 1 \text { year and more improved dyspnoea and fatigue scores }\end{array}$ \\
\hline \multicolumn{6}{|r|}{ ortire in patients witn lorasemiae } \\
\hline Felker, 2011 (35) & 308 & ADHF & $\begin{array}{l}\text { prospective, } 2 \times 2 \text { factorial design, double-blind, } \\
\text { randomized trial }\end{array}$ & $\begin{array}{l}\text { IV Furosemide bolus low Vs high dose Vs } \\
\text { Continuous low VS high dose }\end{array}$ & $\begin{array}{l}\text { Over } 72 \text { hours. No difference for symptoms or renal function } \\
\text { between IV bolus vs continuous infusion. } \\
\text { Higher dose ( } 2.5 x \text { oral dose at admission) had better } \\
\text { secondary outcomes such as relief of dysnpnoea, } \\
\text { change in weight, fluid loss, with worsening renal function, } \\
\text { but there was no worse } 60 \text {-day } \\
\text { outcome. }\end{array}$ \\
\hline \multicolumn{6}{|c|}{ Combined thiazide and Loop Diuretic } \\
\hline Sigurd, 1975 (49) & 18 & ADHF & Randomised cross-over trial, single dose & Bumetanide and Bendrofluazide & More diuresis with combined treatment. \\
\hline Channer, 1994 (50) & 33 & ADHF & Randomised & Iv Furosemide and Bendrofluazide or metolazone & $\begin{array}{l}\text { Bendrofluazide and metolazone were equally effective } \\
\text { in establishing a diuresis }\end{array}$ \\
\hline
\end{tabular}

Figure 2. Renin-angiotensin-aldosterone system (RAAS). 
but a meta-analysis of three short-term studies reporting mortality (follow-up ranging from 1 - 12 months) suggested a $75 \%$ reduction $[95 \%$ CI $16 \%-93 \% \mathrm{P}=0.03$ ] in the risk of death, however the number of deaths were low (12 in the placebo group and 3 in the diuretic group), and the majority of the patients within the meta-analysis were unlikely to have met the contemporary definition of ADHF [26].

\subsection{Thiazide versus Loop Diuretic}

The evidence from several small studies (studies with more than 10 patients are listed in Figure 2) suggests that loop diuretics are more effective than thiazides alone in the management of HF $[25,27,28]$. Thiazides are also more likely to result in hypokalaemia and hyponatreamia $[14,25,29]$. Patients may prefer thiazides, however, as they have a less harsh onset and longer duration of action [30].

\subsection{Comparison between Loop Diuretics}

In the past 20 years the only head-to-head comparisons between loop diuretics have been between torasemide and furosemide. Four of these studies were randomized [31-34]; see Figure 2, but only two enrolled patients with acute decompensated heart failure [32,33], both in the USA. Both of these studies were unblinded. At 12 months Stroupe [32] reported half the risk of readmission in the torasemide-treated group ( $18 \%$ vs $34 \% ; \mathrm{P}=0.013)$, but the larger study by Murray [33] reported no difference in all-cause rehospitalization, although HF readmission was reduced in those taking torasemide $(19 \%$ vs $32 \% \mathrm{P}<0.01)$.

A randomized open-label study in primary care confirmed that torasemide was better tolerated than furosemide, with less urgency to micturate and less daily restrictions reported by the 237 patients, but there was no difference in the risk of hospitalization, adverse events, or mortality [34].

In general, international guidelines do not favor one loop diuretic over another $[7,8]$

\subsection{Dose of Loop Diuretic}

The Diuretic Optimization Strategies Evaluation (DOSE) trial is the largest prospective, double blind, randomized ADHF trial to evaluate initial diuretic strategies in patients with acute decompensated heart failure [35]. Using a $2 \times 2$ factorial design, the DOSE trial randomized 308 ADHF patients to IV furosemide given as twice-daily boluses or continuous infusion and to either a low dose (IV dose numerically equivalent to the patient's oral dose) or a high dose (2.5 times oral dose given intravenously) strategy, with specified dose adjustments permitted after the first 48 hours.

There was no significant difference in either of the coprimary endpoints of global assessment of symptoms, or change in serum creatinine over $72 \mathrm{~h}$, with diuretic administration by bolus or continuous infusion or with a low- versus a high-dose strategy. However, patients randomized to the higher dose strategy had a more favorable outcome with regard to several secondary measures, including relief of dyspnea $(\mathrm{P}=0.04)$, change in weight $(\mathrm{P}$ $=0.01)$, and net fluid loss $(\mathrm{P}=0.01)$, albeit with a greater risk of serum creatinine increasing by $>0.3 \mathrm{mg} / \mathrm{dl}$ within 72 hours $(23 \%$ versus $14 \%, \mathrm{P}=0.04)$. There was no difference in length of initial hospital stay, or in days alive and out of hospital at day 60 .

The trial data therefore suggest that a strategy of using higher doses of diuretics on admission to hospital with ADHF is likely to more rapidly control fluid retention and relieve symptoms, at the cost of a slightly higher risk of renal dysfunction that does not appear to have medium-term consequences.

\subsection{Bolus versus Continuous Infusion of Loop Diuretic}

In the DOSE trial [35] there was no statistically significant difference between continuous infusion or twice daily bolus injection of furosemide in terms of the patients' global assessment of symptoms, mean change in serum creatinine, net fluid loss, change in weight or length of hospital stay. This confirmed the result of an earlier single-centre randomized but single-blind study [36].

\subsection{Use of Hypertonic Saline to Facilitate Effect of Loop Diuretics}

One group has published several randomised studies where the combination of hypertronic saline infusion $(150 \mathrm{ml}$ of $3 \% \mathrm{NaCl})$ with a furosemide $250 \mathrm{mg}$ infusion appeared superior to furosemide alone. All of the studies have been single-blind, but have reported increased diuresis and serum sodium levels, and a reduction in initial hospitalization length of stay. Mortality is also reported to be reduced on follow-up as is readmission rate, with the largest study of 1771 patients reporting a mortality of $12.9 \%$ versus $23.8 \% \mathrm{P}<0.0001$, and readmission proportion of $18.5 \%$ versus $34.2 \%$ over a median follow up of 57 months $(\mathrm{P}<0.0001)$ [37]. The proposed mechanism of action is expansion of intravascular volume, improved renal blood flow, and shift of fluid from the interstitium into the circulating volume [38].

This method of increasing diuresis has not been endorsed by international guidelines, and further studies from other groups are awaited. 


\section{DIURETIC RESISTANCE}

There is no accepted definition of diuretic resistance. Often diuretic resistance is described when higher doses of diuretics are needed to gain a similar diuretic response, or when the diuretic response is either diminished or lost before the therapeutic goal is reached. Diuretic resistance is associated with a poor prognosis [39], and has been reported in occur in up to a third of hospitalized patients [40].

Mechanism involved in diuretic resistance are illustrated in Figure 3, and include:

- Decreased drug bioavailability: increased peripheral and bowel wall oedema, leading to reduced absorption of the diuretic, in particular with oral furosemide $[41,42]$.

- Reduced glomerular filtration rate: may occur secondary to a reduced renal perfusion due to low cardiac output or venous congestion. Chronic kidney disease, or acute kidney injury, can prevent diuretics exerting their beneficial effects. For example, furosemide has to be secreted by the organic acid transporter in the proximal tubule to reach its site of action [43]: reduced GFR can therefore reduce delivery or reduce active secretion of loop diuretics.

- Excessive sodium uptake in the proximal tubule and the loop of Henle: may occur secondary to the following mechanisms:

- Excessive neuro-hormonal activation (renin-angiotensin system);

- The presence of the Braking phenomenon: occurs in the period between boluses of loop diuretic, when there is no diuretic in the proximal tubule or at the loop of Henle, leading to rebound excessive sodium reabsorption at both the proximal tubule and loop of Henle;

- The reduced active secretion of loop diuretic into the proximal tubule can also lead to less diuretic being delivered to site of action leading to less diuresis;

- Excessive sodium intake can also lead to diuretic resistance due to excessive sodium uptake in the proximal tubule.
Reduced GFR may occur secondary to

- Abnormal glomerular haemodynamics (e.g. NSAIDS)

- Reduced renal perfusion from low cardiac output states or venous congestion

- Worsening renal function and chronic kidney disease

These states can reduce delivery of diuretics, reduce active secretion of loop diuretic into tubule

- $\quad$ Excessive Aldosterone and vasopressin mediated sodium and water retention respectively

Excessive sodium uptake in the proximal tubule, may occur secondary to

- Excessive neuro-hormonal activation;

- Braking phenomenon (when there is no diuretic in the tubule, leading to rebound excessive sodium resorption)

- Reduce active secretion of loop diuretic into tubule therefore less diuresis

- Excessive sodium intake

Excessive sodium resorption in the Loop of Henle because of:

- Braking phenomenon (when there is no diuretic in the tubule, leading to rebound excessive sodium resorption)
Renal Adaptation

- Chronic diuretic use can lead to excessive amounts of sodium arriving in the distal tubule leading to distal tubule hypertrophy leading to rebound sodium rentention

Excessive Sodium and water retention in the distal Nephron and collecting ducts may occur secondary to

\section{Cortex - Excessive Aldosterone and} vasopressin mediated sodium and water retention respectively

Medulla

Non-nephron related cause of diuretic resistance

- $\quad$ Reduced drug bioavailability (especially with oral furosemide) due to reduced absorption from the edematous bowel

Figure 3. Mechanisms of diuretic resistance. 
- Renal adaptation: chronic diuretic use results in increased delivery of sodium to the distal convoluted tubule, which consequently hypertrophies $[44,45]$, and can therefore retain more sodium (and water) than a diuretic naïve patient.

- Excessive sodium and water retention in the distal nephron and collecting ducts may occur secondary to excessive aldosterone and vasopressin mediated sodium and water retention, respectively

- Drug interaction: NSAIDS, aspirin [46], steroids, pioglitazone

- Pseudoresistance: poor compliance with diuretics can be misinterpreted as diuretic resistance. A good clinical history can help identify this, as can discussions with the patient's family or carer.

\section{OVERCOMING DIURETIC RESISTANCE}

Several strategies can be employed in an attempt to overcome diuretic resistance in a patient with acute decompensated heart failure.

\subsection{Diuretic Strategies}

These include: changing the route of administration from oral to intravenous (thus overcoming bioavailability issues); continuous infusion of loop diuretic rather than intermittent bolus injections (minor effect); using higher doses of intravenous loop diuretics to increase dose reaching the tubules, particularly when glomerular filtration is poor; sequential nephron blockade by using a combination of diuretics [47-50] such as metolazone or bendroflumethazide in addition to a loop diuretic. Two of these randomized studies are summarized in Figure 2. This approach requires particularly close monitoring as it can lead to marked electrolyte disturbance, hypotension, dehydration and worsening renal function.

In some patients, restricting excessive dietary sodium and fluid intake can also help reduce diuretic resistance by reducing the sodium and fluid load arriving at the nephron.

\subsection{Non-Diuretic Strategies}

There are several non-diuretic strategies to enhance the effectiveness of diuretic therapy.

\subsubsection{Renal Dose Dopamine}

Dopamine has a dose-dependent mechanism of action. At doses of $2-3 \mu \mathrm{g} / \mathrm{kg} / \mathrm{min}$ (renal dose dopamine) the drug acts on peripheral dopaminergic receptors (DA1 and DA2) resulting in vasodilation in the renal, coronary, splanchnic and cerebral circulations. At doses of 3 - 5 $\mu \mathrm{g} / \mathrm{kg} / \mathrm{min}$, it acts as a $\beta$-agonist, and at higher doses (5 -
$15 \mu \mathrm{g} / \mathrm{kg} / \mathrm{min}$ ) it acts also as an $\alpha$-agonist inducing peripheral vasoconstriction [8]. The exact mechanism through which dopamine increases renal blood flow remains debated, but is likely to be related to an increase in cardiac output [51] and renal and peripheral vasodilation [52]. The latter effect may be less in advanced heart failure, with selective loss in renal vasodilating capacity [51].

"Renal dose" dopamine together with intravenous furosemide infusion is often used in patients with low systolic blood pressure who have demonstrated a poor response to furosemide infusion alone, although the evidence base for this approach is weak.

The recent Dopamine in Acute Decompensated Heart Failure (DAD-HF) Trial in 60 patients, compared continuous 8-h high-dose furosemide infusion $(20 \mathrm{mg} / \mathrm{h})$ with the combination of low-dose furosemide infusion (5 $\mathrm{mg} / \mathrm{h})$ plus low- dose dopamine $(5 \mu \mathrm{g} / \mathrm{kg} / \mathrm{min})$. Both strategies had a similar effect on total diuresis, and changes in dyspnea score, but worsening renal function was less common in the dopamine group ( $7 \%$ versus $30 \% \mathrm{P}=$ 0.04 ) and serum potassium fell less in the dopamine group. There was no difference in length of stay, or in 60-day mortality or rehospitalization rates [53].

The Renal Optimization Strategies Evaluation in Acute Heart Failure (ROSE-AHF) trial is currently comparing the efficacy and safety of low dose dopamine versus intravenous nesiritide versus placebo in patients with ADHF treated with loop diuretics (NCT01132846).

\subsubsection{Aquaretics}

Vasopressin 2 receptor antagonists, such as tolvaptan, may promote an aquaresis by blocking the effects of vasopressin on the vasopressin 2 receptors located in the collecting ducts, thus blocking the resorption of free water as urine passes through the collecting ducts. This promotes water clearance without having an effect on sodium balance. In the Efficacy of Vasopressin Antagonism in Heart Failure Outcome Study with Tolvaptan (EVEREST) trial, involving over 4100 patients with ADHF, tolvaptan at a dose of $30 \mathrm{mg}$ once per day for a minimum of 60 days had no effect on total mortality or HF hospitalization when compared to placebo $[54,55]$. Tolvaptan did significantly improve hyponatremia in the patients with a baseline serum sodium less than 134 $\mathrm{mmol} / \mathrm{l}$ (sodium increased by $5.40 \mathrm{mmol} / \mathrm{l}$ at day 7 or discharge, compared with an increase of only $1.85 \mathrm{mmol} / 1$ in the placebo group $(\mathrm{P}<0.001))$ and edema score at day 7 (P $<0.003$, with $74 \%$ of tolvaptan patients reporting an improvement in pedal edema by at least 2 grades compared with $70 \%$ of placebo patients). The effect on serum sodium was maintained throughout a maximum of 40 weeks of treatment. The drug has not been licensed for use in ADHF. 


\subsubsection{Adenosine antagonists}

Adenosine antagonists can potentially increase glomerular filtration, and enhance the diuretic effect of diuretic drugs. Despite promising early phase data, the placebocontrolled randomized study of the selective A1 adenosine receptor antagonist rolofylline for patients hospitalized with acute decompensated heart failure and volume overload to assess treatment effect on congestion and renal function (PROTECT) trial, involving 2033 patients with heart failure and renal dysfunction, reported that the adenosine antagonist, rolofylline, did not have any beneficial effects, and was associated with an increased risk of seizures [56].

\subsubsection{Ultrafiltration}

Acute decompensated heart failure patients with refractory oedema unresponsive to diuretic therapy may be considered for ultrafiltration (UF). This method is very effective at removing plasma fluid from blood across a semipermeable membrane, and the recent development of veno-venous peripheral UF with devices that focus on UF alone has positioned UF as a potential alternative to loop diuretics in ADHF [57]. Small studies suggest that UF improves pulmonary and peripheral edema, lung function and hemodynamics without adverse effects on renal function [58,59]. UF can remove fluid relatively rapidly, at rates of up to $400 \mathrm{ml} /$ hour, but in practice $200-300$ $\mathrm{ml} /$ hour is considered adequate. Lower rates may be used if there is significant right ventricular disease or pulmonary arterial hypertension. The fluid removal rate is reevaluated using clinical assessment and serial hematocrit measurements to ensure adequate vascular compartment refill $[59,60]$, and help prevent further renin angiotensin aldosterone system activation, hypotension, and renal injury [61]. Another advantage of UF is that more sodium can be removed (and less potassium) as compared to diuretic therapy [62].

In randomized trials, the typical treatment period has been 24 hours, but UF membranes can last up to 72 hours with care.

There are three key trials of UF in patients with ADHF. The first, Relief for Acutely Fluid Overloaded Patients with Decompensated Congestive Heart Failure (RAPIDCHF), was a proof of concept study of 40 patients with ADHF randomized to a single 8 hour period of UF or to usual care [63]. There was no significant difference between UF and usual care for the primary end point of weight loss at 24 hours, but fluid removal after $24 \mathrm{~h}$ was significantly greater with UF, with significantly improved dyspnea and HF symptoms at $48 \mathrm{~h}$ in the UF group. The second trial was the Ultrafiltration versus Intravenous Diuretics for patients hospitalized for acutely decompensated heart failure (UNLOAD) trial [58], which enrolled 200 patients with ADHF, unblinded and randomized to either UF or loop diuretic therapy within $24 \mathrm{~h}$ of hospitalization. The co-primary endpoints of the UNLOAD trial were weight loss and dyspnea relief at $48 \mathrm{~h}$. The UF group had greater weight loss $(5.0 \pm 3.1 \mathrm{~kg}$ vs $3.1 \pm 3.5$ $\mathrm{kg} ; \mathrm{P}<0.001)$, but there was no difference in the patient-reported outcome of dyspnea. Patients with UF also had lower rates of rehospitalization for HF compared with diuretic therapy (16 of 86 UF patients vs 28 of 87 usual care patients; $\mathrm{P}<0.04)$. There was significantly less hypokalemia and also no difference in serum creatinine with UF compared with diuretics. The third trial is the recently published Effectiveness of Ultrafiltration in Treating People with Acute Decompensated Heart Failure and Cardiorenal Syndrome (CARESS-HF) study [64]. This trial looked at 198 patients with ADHF, worsened renal function and persistent volume overload and patients were randomized to a strategy of UF versus stepped pharmacological management with a primary endpoint of the change in serum creatinine and change in weight considered as a bivariate endpoint at $96 \mathrm{~h}$. This trial showed that UF at a removal rate of $200 \mathrm{ml} /$ hour of fluid was inferior to stepped pharmacological therapy for the primary end point, owing to an increase creatinine level at 96 hours $(20.3 \pm 61.9$ vs $-3.5 \pm 46.9 \mu \mathrm{mol} / 1 ; \mathrm{P}=0.003)$. There was no difference in weight between the UF and stepped pharmacological therapy at 96 hours, with a mean of $5.5 \mathrm{Kg}$ weight loss. UF was associated with higher rate of adverse events related to hypotension or filter problems.

International guidelines suggest that despite these recent trials, further trials are required to assess the exact role of UF in ADHF [8]. Furthermore, the economic impact of UF as an initial strategy for ADHF remains uncertain, and the recent review on the financial implications of UF highlighted the high costs of disposable materials and staff training [65].

In our experience, patients who are unsuitable candidates for UF include those with poor venous access, those in cardiogenic shock requiring inotropic support, and patients with advanced renal disease in whom renal replacement therapy with hemofiltration would be more appropriate.

\section{CONCLUSIONS}

Diuretics have an important role in the management of ADHF. Although the evidence base is not extensive, they remain the mainstay of first line therapy. International guidelines endorse the use of diuretic therapy for the relief of symptoms of congestion, and their use is likely to remain key to clinical management for the forseeable future.

The initial management strategy is likely to be a loop diuretic, such as furosemide, and the evidence suggests 
that an initial "high dose" strategy either by twice daily bolus injection or continuous infusion is likely to be more successful than a slower, more "ramped" approach. In cases of diuretic resistance, adding a thiazide or thiazide like diuretic can enhance diuresis, although close monitoring of fluid balance and electrolytes is necessary. This strategy can also be useful in patients with significant renal dysfunction. Low dose (renal dose) dopamine infusion can improve the effectiveness of diuretic therapy, and help maintain renal function, although the evidence base for this is also limited. Mechanical ultrafiltration is increasingly used for the treatment of fluid retention and/or diuretic resistance, but further trials are required to assess which patients would benefit most from this treatment modality.

\section{REFERENCES}

[1] Southey, R. (1877) Chronic parenchymatous nephritis of right kidney, left kidney small, atrophied. Old scrofulous pyelitis. Transactions of the Clinical Society of London, 10, 152-156.

[2] Krishnakumar, N., Harikrishnan, S. and Tharakan, J.M. (2007) Self-blood letting in congestive cardiac failure. International Journal of Cardiology, 114, 135-136.

[3] Withering, W. (1785) An account of the foxglove and some of its medical uses: With practical remarks on dropsy and other diseases. J \& J Robinson, Yellowknife. doi:10.5962/bhl.title.3869

[4] Vogl, A. (1950) The discovery of the organic mercurial diuretics. American Heart Journal, 39, 881-883.

[5] Novello, F.C. (1957) Benzothiadiazine dioxides as novel duiretics. Journal of the American Chemical Society, 79, 2028. doi:10.1021/ja01565a079

[6] Robson, A.O., Kerr, D.N., Ashcroft, R. and Teasdale, G. (1964) The diuretic response to frusemide. Lancet, 2, 1085-1088.

[7] Jessup, M., Abraham, W.T., Casey, D.E., Feldman, A.M., Francis, G.S., Ganiats, T.G., et al. (2009) 2009 focused update: ACCF/AHA Guidelines for the Diagnosis and Management of Heart Failure in Adults: A report of the American College of Cardiology Foundation/American Heart Association Task Force on Practice Guidelines: Developed in collaboration with the International Society for Heart and Lung Transplantation. Circulation, 119, 1977-2016.

[8] McMurray, J.J., Adamopoulos, S., Anker, S.D., Auricchio, A., Bohm, M., Dickstein, K., et al. (2012) ESC guidelines for the diagnosis and treatment of acute and chronic heart failure 2012: The Task Force for the Diagnosis and Treatment of Acute and Chronic Heart Failure 2012 of the European Society of Cardiology. Developed in collaboration with the Heart Failure Association (HFA) of the ESC. European Journal of Heart Failure, 14, 803869.

[9] Maxwell, A.P., Ong, H.Y. and Nicholls, D.P. (2002) Influence of progressive renal dysfunction in chronic heart failure. European Journal of Heart Failure, 4, 125-30.

[10] Wilson, T.W., McCauley, F.A. and Wells, H.D. (1986) Effects of low-dose aspirin on responses to furosemide. Journal of Clinical Pharmacology, 26, 100-105.

[11] Brater, D.C., Chennavasin, P. and Dehmer, G.J. (1984) Prolonged hemodynamic effect of furosemide in congestive heart failure. American Heart Journal, 108, 10311032.

[12] Johnston, G.D., Nicholls, D.P. and Leahey, W.J. (1984) The dose-response characteristics of the acute non-diuretic peripheral vascular effects of frusemide in normal subjects. British Journal of Clinical Pharmacology, 18, 75-81.

[13] Rybak, L.P. (1985) Furosemide ototoxicity: Clinical and experimental aspects. The Laryngoscope, 95, 1-14.

[14] Vermeulen, A. and Chadha, D.R. (1982) Slow-release furosemide and hydrochlorothiazide in congestive cardiac failure: A controlled trial. Journal of Clinical Pharmacology, 22, 513-519.

[15] Dargie, H.J., Allison, M.E., Kennedy, A.C. and Gray, M.J. (1972) High dosage metolazone in chronic renal failure. British Medical Journal, 4, 196-198.

[16] Townsend, H.A., Waddy, A.L., Eason, C.T. and Richards, H.H. (1984) Frusemide/amiloride combination (Frumil) in heart failure: An open, multi-centre study in general practice. Current Medical Research and Opinion, 9, 132140.

[17] Ghosh, A.K., Mankikar, G., Strouthidis, T., Windsor, A., Long, C. and Glover, D.R. (1987) A single-blind, comparative study of hydrochlorothiazide/amiloride (Moduret 25) and hydrochlorothiazide/triamterene (dyazide) in elderly patients with congestive heart failure. Current Medical Research and Opinion, 10, 573-579.

[18] Kohvakka, A. (1988) Maintenance of potassium balance during long-term diuretic therapy in chronic heart failure patients with thiazide-induced hypokalemia: Comparison of potassium supplementation with potassium chloride and potassium-sparing agents, amiloride and triamterene. International Journal of Clinical Pharmacology, Therapy, and Toxicology, 26, 273-277.

[19] Krishna, G.G., Shulman, M.D. and Narins, R.G. (1988) Clinical use of the potassium-sparing diuretics. Seminars in Nephrology, 8, 354-364.

[20] Kourouklis, C., Christensen, O. and Augoustakis, D. (1976) Bumetanide in congestive heart failure. Current Medical Research and Opinion, 4, 422-431.

[21] Haerer, W., Bauer, U., Sultan, N., Cernoch, K., Mouselimis, N., Fehske, K.J., et al. (1990) Acute and chronic effects of a diuretic monotherapy with piretanide in congestive heart failure-A placebo-controlled trial. Cardiovascular Drugs and Therapy/Sponsored by the International Society of Cardiovascular Pharmacotherapy, 4, 515-521.

[22] Kleber, F.X. and Thyroff-Friesinger, U. (1990) Treatment of mild chronic congestive heart failure with ibopamine, hydrochlorothiazide, ibopamine plus hydrochlorothiazide or placebo. A double-blind comparative study. Cardiology, 77, 67-74. 
[23] Patterson, J.H., Adams Jr., K.F., Applefeld, M.M., Corder, C.N. and Masse, B.R. (1994) Oral torsemide in patients with chronic congestive heart failure: Effects on body weight, edema, and electrolyte excretion. Torsemide Investigators Group. Pharmacotherapy, 14, 514-521.

[24] Sherman, L.G., Liang, C.S., Baumgardner, S., Charuzi, Y., Chardo, F. and Kim, C.S. (1986) Piretanide, a potent diuretic with potassium-sparing properties, for the treatment of congestive heart failure. Clinical Pharmacology and Therapeutics, 40, 587-594.

[25] Stewart, J.H. and Edwards, K.D. (1965) Clinical comparison of frusemide with bendrofluazide, mersalyl, and ethacrynic acid. British Medical Journal, 2, 1277-1281.

[26] Faris, R., Flather, M., Purcell, H., Henein, M., PooleWilson, P. and Coats, A. (2002) Current evidence supporting the role of diuretics in heart failure: A meta analysis of randomised controlled trials. International Journal of Cardiology, 82, 149-158.

[27] Crawford, R.J., Allman, S., Gibson, W., Kitchen, S. and Richards, H.H. (1988) A comparative study of frusemideamiloride and cyclopenthiazide-potassium chloride in the treatment of congestive cardiac failure in general practice. The Journal of International Medical Research, 16, 143149.

[28] Gonska, B.D. and Kreuzer, H. (1985) Diuretic monotherapy in heart failure. Comparison of piretanide and hydrochlorothiazide-triamterene. Deutsche Medizinische Wochenschrift, 110, 1812-1816.

[29] Gabriel, R. and Baylor, P. (1981) Comparison of the chronic effects of bendrofluazide, bumetanide and frusemide on plasma biochemical variables. Postgraduate Medical Journal, 57, 71-74.

[30] Funke Kupper, A.J., Fintelman, H., Huige, M.C., Koolen, J.J., Liem, K.L. and Lustermans, F.A. (1986) Cross-over comparison of the fixed combination of hydrochlorothiazide and triamterene and the free combination of furosemide and triamterene in the maintenance treatment of congestive heart failure. European Journal of Clinical Pharmacology, 30, 341-343.

[31] Noe, L.L., Vreeland, M.G., Pezzella, S.M. and Trotter, J.P. (1998) A pharmacoeconomic assessment of torsemide and furosemide in the treatment of patients with congestive heart failure. Clinical Therapeutics, 21, 854866. doi:10.1016/S0149-2918(99)80007-1

[32] Stroupe, K.T., Forthofer, M.M., Brater, D.C. and Murray M.D. (2000) Healthcare costs of patients with heart failure treated with torasemide or furosemide. Pharmaco Economics, 17, 429-440. doi:10.2165/00019053-200017050-00002

[33] Murray, M.D., Deer, M.M., Ferguson, J.A., Dexter, P.R., Bennett, S.J., Perkins, S.M., et al. (2001) Open-label randomized trial of torsemide compared with furosemide therapy for patients with heart failure. The American journal of medicine, 111, 513-520. doi:10.1016/S0002-9343(01)00903-2

[34] Muller, K., Gamba, G., Jaquet, F. and Hess, B. (2003) Torasemide vs. furosemide in primary care patients with chronic heart failure NYHA II to IV-Efficacy and quality of life. European journal of heart failure, 5, 793-801.
doi:10.1016/S1388-9842(03)00150-8

[35] Felker, G.M., Lee, K.L., Bull, D.A., Redfield, M.M., Stevenson, L.W., Goldsmith, S.R., et al. (2011) Diuretic strategies in patients with acute decompensated heart failure. The New England Journal of Medicine, 364, 797-805. doi:10.1056/NEJMoa1005419

[36] Allen, L.A., Turer, A.T., Dewald, T., Stough, W.G., Cotter, G. and O'Connor, C.M. (2010) Continuous versus bolus dosing of Furosemide for patients hospitalized for heart failure. The American journal of cardiology, 105, 1794-1797. doi:10.1016/j.amjcard.2010.01.355

[37] Paterna, S., Fasullo, S., Parrinello, G., Cannizzaro, S., Basile, I., Vitrano, G., et al. (2011) Short-term effects of hypertonic saline solution in acute heart failure and long-term effects of a moderate sodium restriction in patients with compensated heart failure with New York Heart Association class III (Class C) (SMAC-HF Study) The American Journal of the Medical Sciences, 342, $27-$ 37. doi:10.1097/MAJ.0b013e31820f10ad

[38] Tuttolomondo, A., Pinto, A., Parrinello, G. and Licata, G. (2011) Intravenous high-dose furosemide and hypertonic saline solutions for refractory heart failure and ascites. Seminars in Nephrology, 31, 513-522. doi:10.1016/j.semnephrol.2011.09.006

[39] Neuberg, G.W., Miller, A.B., O’Connor, C.M., Belkin, R.N., Carson, P.E., Cropp, A.B., et al. (2002) Diuretic resistance predicts mortality in patients with advanced heart failure. American Heart Journal, 144, 31-38. doi:10.1067/mhj.2002.123144

[40] Ravnan, S.L., Ravnan, M.C. and Deedwania, P.C. (2002) Pharmacotherapy in congestive heart failure: Diuretic resistance and strategies to overcome resistance in patients with congestive heart failure. Congest Heart Fail, 8, 80-85. doi:10.1111/j.1527-5299.2002.0758.x

[41] Brater, D.C., Day, B., Burdette, A. and Anderson, S. (1984) Bumetanide and furosemide in heart failure. Kidney International, 26, 183-189. doi:10.1038/ki.1984.153

[42] Vasko, M.R., Cartwright, D.B., Knochel, J.P., Nixon, J.V. and Brater, D.C. (1985) Furosemide absorption altered in decompensated congestive heart failure. Annals of Internal Medicine, 102, 314-318. doi:10.7326/0003-4819-102-3-314

[43] De Silva, R., Nikitin, N.P., Witte, K.K., Rigby, A.S., Goode, K., Bhandari, S., et al. (2006) Incidence of renal dysfunction over 6 months in patients with chronic heart failure due to left ventricular systolic dysfunction: Contributing factors and relationship to prognosis. European Heart Journal, 27, 569-581. doi:10.1093/eurheartj/ehi696

[44] Stanton, B.A. and Kaissling, B. (1988) Adaptation of distal tubule and collecting duct to increased Na delivery. II. $\mathrm{Na}+$ and $\mathrm{K}+$ transport. The American Journal of Physiology, 255, F1269-F1275.

[45] Kaissling, B. and Stanton, B.A. (1988) Adaptation of distal tubule and collecting duct to increased sodium delivery. I. Ultrastructure. The American journal of physicology, 255, F1256-F1268.

[46] Bartoli, E., Arras, S., Faedda, R., Soggia, G., Satta, A. 
and Olmeo, N.A. (1980) Blunting of furosemide diuresis by aspirin in man. Journal of Clinical Pharmacology, 20, 452-458. doi:10.1002/j.1552-4604.1980.tb01718.x

[47] Kiyingi, A., Field, M.J., Pawsey, C.C., Yiannikas, J., Lawrence, J.R. and Arter, W.J. (1990) Metolazone in treatment of severe refractory congestive cardiac failure. Lancet, 335, 29-31. doi:10.1016/0140-6736(90)90148-X

[48] Dormans, T.P. and Gerlag, P.G. (1996) Combination of high-dose furosemide and hydrochlorothiazide in the treatment of refractory congestive heart failure. European Heart Journal, 17, 1867-1874. doi:10.1093/oxfordjournals.eurheartj.a014805

[49] Sigurd, B., Olesen, K.H. and Wennevold, A. (1975) The supra-additive natriuretic effect addition of bendroflumethiazide and bumetanide in congestive heart failure. Permutation trial tests in patients in long-term treatment with bumetanide. American Heart Journal, 89, 163-170. doi:10.1016/0002-8703(75)90041-1

[50] Channer, K.S., McLean, K.A., Lawson-Matthew, P., Richardson, M. (1994) Combination diuretic treatment in severe heart failure: A randomised controlled trial. British Heart Journal, 71, 146-150. doi:10.1136/hrt.71.2.146

[51] Bock, J.S. and Gottlieb, S.S. (2010) Cardiorenal syndrome: New perspectives. Circulation, 121, 2592-2600. doi:10.1161/CIRCULATIONAHA.109.886473

[52] Elkayam, U., Ng, T.M., Hatamizadeh, P., Janmohamed, M. and Mehra, A. (2008) Renal vasodilatory action of dopamine in patients with heart failure: Magnitude of effect and site of action. Circulation, 117, 200-205. doi:10.1161/CIRCULATIONAHA.107.737106

[53] Giamouzis, G., Butler, J., Starling, R.C., Karayannis, G., Nastas, J., Parisis, C., et al. (2010) Impact of dopamine infusion on renal function in hospitalized heart failure patients: Results of the dopamine in acute decompensated heart failure (DAD-HF) trial. Journal of Cardiac Failure, 16, 922-930. doi:10.1016/j.cardfail.2010.07.246

[54] Konstam, M.A., Gheorghiade, M., Burnett, J.C., Jr. Grinfeld, L., Maggioni, A.P., Swedberg, K., et al. (2007) Effects of oral tolvaptan in patients hospitalized for worsening heart failure: The everest Outcome Trial. JAMA: The Journal of the American Medical Association, 297, 1319-1331. doi:10.1001/jama.297.12.1319

[55] Gheorghiade, M., Konstam, M.A., Burnett, J.C., Jr. Grinfeld, L., Maggioni, A.P., Swedberg, K., et al. (2007) Short-term clinical effects of tolvaptan, an oral vasopressin antagonist, in patients hospitalized for heart failure: The everest clinical status trials. JAMA: The Journal of the American Medical Association, 297, 13321343. doi:10.1001/jama.297.12.1332

[56] Massie, B.M., O’Connor, C.M., Metra, M., Ponikowski, P., Teerlink, J.R., Cotter, G., et al. (2010) Rolofylline, an adenosine A1-receptor antagonist, in acute heart failure.
The New England Journal of Medicine, 363, 1419-1428. doi:10.1056/NEJMoa0912613

[57] Jaski, B.E., Ha, J., Denys, B.G., Lamba, S., Trupp, R.J. and Abraham, W.T. (2003) Peripherally inserted venovenous ultrafiltration for rapid treatment of volume overloaded patients. Journal of Cardiac Failure, 9, 227- 231. doi:10.1054/jcaf.2003.28

[58] Costanzo, M.R., Guglin, M.E., Saltzberg, M.T., Jessup, M.L., Bart, B.A., Teerlink, J.R., et al. (2007) Ultrafiltration versus intravenous diuretics for patients hospitalized for acute decompensated heart failure. Journal of the American College of Cardiology, 49, 675-683. doi:10.1016/j.jacc.2006.07.073

[59] Schroeder, K.L., Sallustio, J.E. and Ross, E.A. (2004) Continuous haematocrit monitoring during intradialytic hypotension: Precipitous decline in plasma refill rates. Nephrology, Dialysis, Transplantation: Official publication of the European Dialysis and Transplant Association-European Renal Association, 19, 652-656.

[60] Marenzi, G., Lauri, G., Grazi, M., Assanelli, E., Campodonico, J. and Agostoni, P. (2001) Circulatory response to fluid overload removal by extracorporeal ultrafiltration in refractory congestive heart failure. Journal of the American College of Cardiology, 38, 963-968. doi:10.1016/S0735-1097(01)01479-6

[61] Marenzi, G., Grazi, S., Giraldi, F., Lauri, G., Perego, G., Guazzi, M., et al. (1993) Interrelation of humoral factors, hemodynamics, and fluid and salt metabolism in congestive heart failure: Effects of extracorporeal ultrafiltration. The American Journal of Medicine, 94, 49-56. doi:10.1016/0002-9343(93)90119-A

[62] Ali, S.S., Olinger, C.C., Sobotka. P.A., Bernard, S., Dahle, T.G., Bunte, M.C., et al. (2006) Enhanced sodium extraction with ultrafiltration compared to intravenous diuretics. Journal of Cardiac Failure, 12, S114. doi:10.1016/j.cardfail.2006.06.393

[63] Bart, B.A., Boyle, A., Bank, A.J., Anand, I., Olivari, M.T., Kraemer, M., et al. (2005) Ultrafiltration versus usual care for hospitalized patients with heart failure: The relief for acutely fluid-overloaded patients with decompensated congestive heart failure (RAPID-CHF) trial. Journal of the American College of Cardiology, 46, 2043-2046. doi:10.1016/j.jacc.2005.05.098

[64] Bart, B.A., Goldsmith, S.R., Lee, K.L., Givertz, M.M., O'Connor, C.M., Bull, D.A., et al. (2012) Ultrafiltration in decompensated heart failure with cardiorenal syndrome. The New England Journal of Medicine, 367, 2296-2304. doi:10.1056/NEJMoa1210357

[65] Kazory, A., Bellamy, F.B. and Ross, E.A. (2012) Ultrafiltration for acute decompensated heart failure: Financial implications. International Journal of Cardiology, 154, 246-249. doi:10.1016/j.ijcard.2011.05.073 